\title{
Managing of change in building sustainable competitiveness for Kosovo companies
}

\author{
HUSNIJA BIBULJICA \\ Business Administration \\ University of Peja \\ Peja \\ KOSOVO \\ EMIN NEZIRAJ \\ Management and Informatics \\ College of Pjeter Budi \\ Pristina \\ KOSOVO
}

\begin{abstract}
Change Management at organizational level has been conceived to be an important aspect of successful change implementation programs in modern organizations. In order to benefit from the efficiency that appropriate management of change offers in structured organizations, the study of management has ascribed importance to the study of change management as a management concept. This study has attempted to review existing literature on the subject. The study presented a conceptual analysis of the concept of change and the principles developed by practitioners for the management of change with connection with building a sustainable competitive ability of companies. A theoretical review of the concept was undertaken with focus on the Kurt Lewin's force field theory which has been generally accepted as the theoretical foundation of change as attested by the acceptance of the theory as the bases for all other theories of change and connection with sustainable competitive ability of companies and this ascribed the title father of change management to main authors of change management. This study analyzed the basis of building competitive ability during of change process in Kosovo companies. The Study adopted a case study research conducted by other researchers to validate the effectiveness of the three stages of effective change management process with the focus of building stages for the sustainable competitive ability of enterprise as propounded by many authors on this field.
\end{abstract}

Key-Words: - Change management, Organizational development, Resistance, Change, Influence

Received: December 11, 2019. Revised: June 8, 2020. Re-revised: June 15, 2020. Accepted June 23, 2020. Published: June 17, 2020.

\section{Introduction}

A very successful company would be the one who could survive in long run in constantly changing world and their managers are good at managing changes . Research conducted among long-standing companies in United States and Europe has shown us that it is one of the reasons why these companies have survived their sensitivity to environment in which they operate [1]. Regardless of whether their business has built up knowledge or natural resources, they have remained in line with world surrounding them. Although there was no access to information like today, as well as access to other resources they managed to respond to conditions and requirements of society around them, in line with conditions that existed at that time [2]. These companies were able to successfully manage its growth, had a

powerful driver for progress which allowed them to change and adapt without compromising their fundamental ideals and values. Time needed to react to the changes in environment is all shorter compared to available time for making changes. Therefore it is important to understand basic concepts, processes and samples of organizational change management as well as their impact on enterprise functioning [3]. Many businesses grow and survive in long run, they create sustainable competitive ability while others are decaying and disappearing. Question arises as to why some organizations have the ability to manage their own strategy, structure and culture in order to gain access to resources from environment, while others fail [4]. Reason can be found in the fact that these companies are able to respond in a timely manner to demands for constant adaptation to environment in order 
to create and maintain their competitive advantage and achieve longevity. Therefore, successful adaptation of changes to the company and demands of environment become one of main sources of sustainable competitive ability and source of longevity of enterprises [5] .This research aims to point out connections that occur between management of changes and competitiveness of enterprise, changes that occur and through which company passes on their "life course" and how change management as well as life cycle of company influences the construction of a sustainable competitive ability of enterprise.

\section{Formulation of problem}

The main part of our research is to determine which elements are crucial for long-term survival of company and extent to which impact of change managing in building a sustainable competitive ability of enterprise. Understanding how organizations develop, grow and vanish or how they change over time is crucial in order to build up the competitiveness of enterprises and enable long-term survival and development.

General (main) hypothesis:

$\mathrm{H}_{\circ}$ - Managing organizational change is closely related to the sustainable competitiveness of enterprises;

Specific (supplementary) hypotheses:

- There is interdependence between life stage cycle of enterprises and organizational changes in long-standing enterprises in Kosovo;

- Successful management of changes in characteristics of long-term companies in Kosovo;

- The long-term enterprises in Kosovo have a modern system of implementation for development strategies;

\subsection{Basic concepts in the field of organizational change}

Although each generation thinks that the degree of change is faced by high degree as well as level of change that today's enterprise face has never been better. Moreover, companies are under pressure from different forces of change coming from their whether internal or external environment. An enterprise is asked to continuously adapt to environment if want to maintain their competitive advantage [6]. Organizational efficiency requires that businesses recognize needs for different types of change and take steps to properly manage them. How to adapt to constant changes in the environment while maintaining stability and need for everyday activities becomes a key issue. Successful adaptation of company [7] to changes and demands of environment becomes one of the main sources of sustainable competitiveness and source of longevity of the company. Today's world and way of life cannot be perceived without understanding the strong influence of organization in it, which makes and enables our everyday life. Organizations follow us from birth to death, with them we are born, created, and we die. An organization can be defined as a tool used by people in coordinating their own activities to get what they want or value, or to achieve their goals.

Organization management is a tool that makes organizations capable of producing results. Primary task of management is to ensure that an organization works efficiently in carrying out its tasks and achieving its goals. Focused on results of organization, management activities start with planned results and organizing company's resources in order to achieve results [5].As the organization works in interaction with its environment and depends to a large extent on it, it is compelled to monitor changes in environment, both internal and external and in accordance with them, carry out certain organizational changes if it aims to survive [1]. Structure and functioning of organization must reflect the nature of environment in which organization operates. Therefore it is necessary to strike a balance between pressures that occur in organization's external environment and those within organization itself [2] . Therefore, managers must continuously identify and find solutions to problems that are consequence of incompatibility components within organization and organization's compliance with its environment.

\subsection{Basic concepts and concepts of organizational change}

Organizational changes are of great importance to the organization. They affect organizational performance; create models and new work 
assignments [8], as well as new social relationships in the workplace. In order to survive especially in the long term, organizations must change and adapt to their own environment. Organizational changes as well as the process of organizational change include a numerical complex set of variables whose interaction, type and impact vary from one situation to another [7]. Certainly strength and importance of environmental change for an organization depends on the type of organization itself, industry and market in which operates. Although changes are conditioned by changing factors around the organization, necessity of change stems from organization's sustained need to be successful. It can be concluded that organizational change is a process by which an organization moves from its current state to a desired future state in order to show its effectiveness [7]. The goal is to find new or improved ways of using resources in order to show organization's ability to create value, its realization as well as goal of individuals within organization [8] Organizational change is actually a shift in how the organization works, its members and leaders, what shape it takes or how they allocate resources. Further definitions of change indicate that it occurs when: - something is done differently; - something gets a different position, direction or characteristic; - something is replaced; - something is being modified; something is transformed or replaced [9].

Change is most often induced by an incentive event, a change in environment that emphasizes need for a strategy change or new forms of employee behavior [4]. Degree of change can vary from one organization to another, but they all face the need to adjust to stimulating forces [10]. Many of these changes are imposed on organizations while others have been created internally or within the organization. Most of the changes are part of the natural aging process of organization. However, the main pressure for change comes from external incentives and forces [12].External incentives for organizational change include: - new technologies; - new materials; - changes in preferences and consumer needs; - competitors' activities and innovations; - legal and state regulations; - changes on domestics and global economic and trade conditions; - changes in local, national and international politics; changes in social and cultural values. Internal incentives for organizational change may include: - innovations in terms of new products and service design; - low functioning and ethics [11], high stress and employee changes; appointment of a new chief manager and executive manager team; inadequate skills and knowledge base which encourages exercise programs; - moving cx offices or factories closer to suppliers and market; - identifying the problems that cause responsibility to be reallocated; - innovation in production process; - new ideas about delivering services to consumers [12]. For easier understanding and meaning of the process of organizational change it is important to understand that any organization, although it is an independent entity that operates among various elements of environment that are set up and through which it can enter in achieving its goal, is at the same time element of environment in which it operates and it is in interaction with your environment [9].

\section{Problem Solution}

\subsection{Empirical material and data collection method}

For the aim of this master's thesis, empirical research was conducted on a sample of enterprises in Kosovo with a long tradition of business. This is the first study of this type after Kosovo's declaration of independence and purpose of such a sample is to investigate what have ensured these enterprises in Kosovo for their longevity and how and to what extent organizational changes influence survival of the company. It also aims to point out changes that are taking place and through which companies pass on their "lifestyle," and that change management and life cycle of the company influences construction of a sustainable competitive ability of the company. Testing general hypothesis will try to point out connection between variables of managing organizational changes and building a sustainable competitive ability of enterprise or to which extent increase in assessment of management value for organizational changes influences increase in assessment of the value for sustainable competitive ability of the enterprise. Each individual phase of life cycle is characterized by specific organizational changes that are specific to a particular phase.

Testing first auxiliary hypothesis on interdependence of life cycle phase and organizational changes, it is necessary to point Volume 16, 2020 
out mentioned relationship that is if the undertakings are located in first phase of life cycle, therefore for these undertakings there will be characteristic organizational changes specific to the first phase of life cycle. Second auxiliary hypothesis is to test extent to which successful changes management in characteristics of long-term enterprises in Kosovo and how certain characteristics of successful management of change are reflected among the companies in Kosovo. Whether there is a specific feature of successful change management that is more pronounced or noncharacteristic of a long-term enterprise in Kosovo will also be tested by testing third hypothesis. Third auxiliary hypothesis is focused on examining development level for implementation system and development strategies in long-term enterprises in Kosovo. Within the mentioned questionnaire a control question was raised in which respondents assessed implementation system for development strategies in their business, as well as the level of system in relation to enterprises from the same industry, and it would also be possible to compare actual and acceptable development of implementation system for development strategies in the company. 33 companies responded to the survey questionnaire sent at the company addresses in Kosovo with a longer business tradition which represents a return rate of $53 \%$. Observing according to activities of enterprises that answered the questionnaire were primarily production enterprises, $69.7 \%$ of them. In a sample was firstly the most frequent service company with $18.2 \%$, afterwards catering (hotels and restaurants) $6.1 \%$, trade $3 \%$ and others $3 \%$. According to ownership forms they are primarily private companies, $57.6 \%$, and then state companies $18.2 \%$ mixed with more than $50 \%$ of private capital $15.2 \%$, cooperative $6.1 \%$, and mixed with more than $50 \%$ of state capital $3 \%$.

\subsection{Research part of the study}

Logistic regression was used to test general hypothesis of managing organizational changes and influencing competitiveness of enterprises in Kosovo. Logistic regression is used when responses are measured on an ordinal scale which also includes the Likert scale used in conducted research. From the surveys questionnaire, attached at the end of the master's thesis, responses were grades as a degree of non-agreement with claims of next intensity: 1 - I strongly disagree; 2 - I do not agree; 3 - I neither agree nor disagree; 4 - I agree; and 5 - I very much agree. The regression analysis consists in applying different methods of testing dependence of one variable on another or more variables, which creates the image of a phenomenon in a relationship. The variables whose variations are explained by means of other names are dependent variable as well as variables explaining variation of dependent variable is called independent variables. In the specific case dependent variable is represented through agreement degree with claims related to viable competitive ability of enterprise, while independent variable is degree of agreement with claims related to management of organizational changes. In testing general hypothesis (zero hypothesis), variable management of organizational changes is not significant in the above mentioned model, while the side-line hypothesis claims that variable management of organizational changes is a significant variation in the model. A 5\% significance level is taken for data interpretation. Hypotheses are:

- Organizational change management $=0$

- Managing organizational change $\neq 0$ 


\begin{tabular}{llr}
\hline Ordinal Logistic Regression: Maintains a c \\
Link Eunction: Logit \\
organizationa \\
Response Information \\
\end{tabular}

Logistic Regression Table

Predictor

Const (1)

Const (2)

Const (3)

Opr org pro

$\begin{array}{rrrrrr}\text { Coet } & \text { SE coet } & 2 & \text { P } & \begin{array}{c}\text { Odds } \\ \text { Ratio }\end{array} & \begin{array}{c}\text { CI } \\ \text { Lower }\end{array} \\ 1,96242 & 2,09008 & 0,94 & 0,348 & & \\ 3,15745 & 2,24128 & 2,30 & 0,021 & & \\ 5,02948 & 2,50446 & 3,25 & 0,001 & & \\ 0,05587 & 0,596078 & -2,31 & 0,021 & 1,06 & 0,03\end{array}$

Log-Likelinood $=-31,860$

Test that all slopes are zero: $G=6,368, \mathrm{DE}=1$, P-Value $=0,012$

Goodness-of-Fit Tests

$\begin{array}{lrrr}\text { Method } & \text { Chi-Square } & \text { DF } & \text { p } \\ \text { Pearson } & 3,95222 & \text { 日 } & 0,861 \\ \text { Deviance } & 5,53766 & \text { 日 } & 0,699\end{array}$

Measures of Association:

(Between the Response Variable and Predicted Probabilities)

\begin{tabular}{lrrll} 
Pairs & Number & Percent & Sumary Measures & \\
Concordant & 158 & 47,9 & Somers' D & 0,39 \\
Discordant & 30 & 9,1 & Goodran-Kruskal Gamma & 0,68 \\
Ties & 142 & 43,0 & Kenda11's Tau-a & 0,24 \\
Total & 330 & 100,0 & & \\
\hline
\end{tabular}

Based on the table it follows that variable increasing competitiveness affects in fact management of changes. The basis of change in increasing competitiveness of the company brings benefits. Goal of logistic regression is to transform obtained answers into a linear form that can be done by logging and such transformations are called quasi-logic transformations.

Thus, the logic regression equation with estimated parameters can be written:
$101 \log$ it $(\pi)=1,962+3,157+5,029+0$, 05587 (upr_org _ pro), where upr_org_pro is an independent variable and denotes management of organizational changes. Recorded method is an additive way. From previously written equation, it can be noted that increasing degree of agreement with management of organizational changes positively influences the $\log$ it $(\pi)$ ratio, which is the ratio (probability) of agreement with sustainable competitive ability of company, represents probability, $\log ()$ logarithmic 
transformation or logit shortly $\log (\pi)$.Managing organizational changes (independent variable) has a significant influence in the model because the $p$-value 0.021 is lower than selected significance level $(\mathrm{p}=0.05)$, which leads to the conclusion that we reject a general hypothesis who asserts that variable is insignificant in the model in favour of an alternative hypothesis that independent variable is significant in model. It is therefore concluded that management of organizational changes is linked to building a viable competitive ability of the company. A particularly important part of regression analysis relates to examination of the state obtained results. A special set is used for regression diagnostic methods. Regression diagram shows how well the model is adapted to data. General (zero) hypothesis in this case states that model does not describe data good, while auxiliary hypothesis assumes that model is well describing data. According to obtained data $p$-value for Pearson's measure and deviation is 0.81 and 0.69 , which shows that there is not enough indication for the claim that model does not describe data well. Selected model is well-adapted to data. The $\mathrm{G}$ ratio shows whether model is significant on its entirety and corresponding p-value is 0.01 , which is less than a certain level of significance $(\mathrm{p}=0.05)$ and proves that model is describing data well.

The control element of proof for this hypothesis can also raise a question by observed enterprises as far as they agree with assertion that management of organizational changes is connected with sustainable competitiveness of enterprise. Evaluating the above mentioned statement by grades 1 to 5 ( 1 - I strongly disagree, 5 - I strongly agree) over $83 \%$ of respondents answered that they agreed and expressly agreed with the stated claim, while $17 \%$ of the observed companies expressed a strong disagreement and indifference. Agreeing with the claim that management of changes is connected with building a sustainable competitive ability of the company.Through the questionnaire survey was researched how many observed companies evaluate the role of individual elements in building convening capability of their company. Thus, as the most important element in building competitiveness highest grade refers to the quality of features and services, with an average score of 4.58 and the smallest range between minimum and maximum possible rating.

Table 2 the statistics description of variables

\begin{tabular}{|c|c|c|c|c|c|c|}
\hline Elements & $\begin{array}{l}\text { Mea } \\
\mathrm{n}\end{array}$ & $\begin{array}{l}\text { Stde } \\
\mathrm{v}\end{array}$ & $\begin{array}{l}\text { Coef.Va } \\
\text { r. }\end{array}$ & $\begin{array}{l}\text { Mo } \\
\text { d }\end{array}$ & $\begin{array}{l}\mathrm{Mi} \\
\mathrm{n}\end{array}$ & $\begin{array}{l}\text { Ma } \\
\text { X. }\end{array}$ \\
\hline $\begin{array}{c}\text { Low } \\
\text { spending } \\
\text { in business }\end{array}$ & 4.96 & 1.03 & $25 \%$ & 5 & 2 & 5 \\
\hline $\begin{array}{l}\text { Quality of } \\
\text { enterprises }\end{array}$ & 4.27 & 0.72 & $17 \%$ & 4 & 2 & 5 \\
\hline $\begin{array}{c}\text { Quality } \\
\text { and obelis } \\
\text { of retail. } \\
\text { and } \\
\text { services }\end{array}$ & 4.58 & 0.56 & $12 \%$ & 5 & 3 & 5 \\
\hline $\begin{array}{l}\text { Reputation } \\
\text { of } \\
\text { undertakin } \\
\mathrm{g} \text { and } \\
\text { assortment }\end{array}$ & 4.21 & 0.74 & $18 \%$ & 4 & 3 & 5 \\
\hline $\begin{array}{c}\text { Achieve } \\
\text { technologi } \\
\text { cal } \\
\text { developme } \\
\text { nt }\end{array}$ & 4.06 & 0.97 & $24 \%$ & 5 & 1 & 5 \\
\hline $\begin{array}{c}\text { Advertisin } \\
\mathrm{g} \\
\text { differences } \\
\text { and sales } \\
\text { activities } \\
\text { compared } \\
\text { to } \\
\text { competitio } \\
\mathrm{n}\end{array}$ & 3.45 & 1 & $29 \%$ & 4 & 2 & 5 \\
\hline
\end{tabular}

Table 2. Importance of certain elements in construction of competitiveness In addition to the quality and characteristics of products and services, quality resources of the company (an average rating of 4.27) and reputation of enterprises as well as assortments (4.21) were evaluated as an important element in the construction of competitive ability. As a source of competitive ability element of difference in marketing and sales activities compared to competition is the lowest with an average score of 3.45 , but 104 with a pronounced deviation from the average of 1 rating, which indicates that some enterprises represent an important source of competitive ability, moreover on one hand and on the other hand, the undertakings in comparison with other elements, are not such an important source of competitiveness. To prove second hypothesis since as with the first hypothesis were used data obtained with the help of ordinal scale, with the second hypothesis will be used the non-parametric test. Testing hypothesis about parameters of basic sets for sample patterns is based on certain theoretical settings as well as they relate to 
distribution form of the basic set. It is often assumed that a random sample of the value of a numerical variable arises from a normal distribution or some sort of competitiveness of a company means finding a way to be ahead of other companies in the market. It is a basic prerequisite for survival companies while building and constantly raising competitiveness becomes a key task of its managers. Companies must be flexible, innovative and continuously improve their business by setting different strategies for purpose of more successful positioning in relation to the competition and for purpose of achieving and / or maintaining a competitive advantage. In the case of first auxiliary hypothesis it is tested existence of interdependence between life cycle of enterprises and organizational changes in enterprises with a longer business tradition in Kosovo that use $\left(\mathrm{X}^{2}\right)$ test of independence characteristics. In order to test this hypothesis we used last five questions from survey questionnaire, that were attached to the master questionnaire related to current phase of life cycle of surveyed enterprises. Questions related to life cycle phase are structured in a way that each individual question related to one dimension of an organization is distinct in particular phases of life cycle.

Table 3 Chi Square of phases

\begin{tabular}{|rrrrrr}
\hline Chi-Square Test: 1 Faza; 2. Faza; 3 Faza; \\
Expected counts are printed below observed counts \\
contributions are printed below
\end{tabular}


Testing process preceded classification of obtained $\mathrm{n}$ data from the sample according to principle of exhaustiveness and exclusivity in the $\mathrm{k}$ group, which resulted in empirical distribution or statistical sequence. This is presented in the first line next to any questions from 1 to 7 . In that line, company responses are grouped with respect to response of characteristic of a particular dimension according to which they are classified into one of the four phases of life cycle and a confirmatory answer to questions related to organizational changes for stated life cycle phase. For example data in matrix 1.1 indicates that 4 companies have given a response that according to this dimension places them in first phase of life cycle and have affirmatively replied to changes 1 and / or 2 relating to changes regarding to the first phase of life cycle. Therefore, because hi-square is smaller (closer to zero), moreover the set hypothesis is to be accepted and that hi-square is larger it is more likely that hypothesis set should be rejected, since observed results differ significantly from those we showed to be under certain hypothesis.

According to obtained values total empirical hisquare is 64,733 , while theoretical hi-square is necessary to calculate with degree of freedom. Degree of freedom is calculated as ( $\mathrm{r}-1)(\mathrm{c}-1)$, where $r$ is the number of column elements and $c$ is the element of order $(\mathrm{r}=7, \mathrm{c}=4$ for the observed data). The degree of freedom is 18 with a level of significance of $5 \%$, the theoretical hi-square test size is obtained from 37.2. Since empirical value of the hi-square test is higher than theoretical test of the hi-square test, with given level of significance zero hypotheses are rejected in favour of alternative one therefore there as interdependence among observed variables. The decision to accept first auxiliary hypothesis can also be confirmed through the p-value, which is 0.021 , so the given level of significance of 5\% reflects zero hypothesis according to which there is no dependence of variables of life cycle phases and organizational changes that accepts first one as an auxiliary hypothesis on the interdependence of life cycle phases and organizational changes in long-term companies in Kosovo. In order for testing to be valid number of analysed data must be large enough and expected frequencies rules says that the sample is large enough if there are more than thirty members, if all the expected frequencies are equal to 2 and higher and if at least $50 \%$ are equal to 5 and higher. Since in observed sample number of members is $30(n=33)$, all expected frequencies are from 2 and only 7 frequencies are less than 5 , it can be concluded that correct application of this test in testing and proving first auxiliary hypothesis there is an interdependence between phase of life cycle and organizational changes in longterm enterprises in Kosovo. The Wilcoxon Signed Rank test was used to test second and third auxiliary hypothesis. As an initial step in testing Wilcoxon Signed Rank hypothesis, a median is determined that divides ordered sequence into two equal parts. In case of the second modest hypothesis degree of agreement was indicated via the Likert scale 1-5. Surveyed company stated how many of these claims relate to their companies when implementing organizational changes (Part E of survey questionnaire), using grades 1 - never; 2- rarely; 3 - sometimes; 4 - often; and 5 - always. Based to the fact that purpose of Wilcoxon Signed Rank test is to determine median basic set and to see concentration of company according to the grades, considering possible estimates of claim as centre value is taken sometimes average grade 3-. General hypothesis claims that the median basic set is less than or equal to grade 3 , while auxiliary hypothesis claims that median basic set is higher than grade 3 on the scale in questionnaire related to success of change management. After observing and calculating middle value for each particular question in relation to another auxiliary hypothesis, decision on which hypothesis is accepted for a particular question brings $108 \mathrm{se}$ through the p-value. With a selected level of significance of $5 \%$, the p-values are all in order except for two questions less than selected level of significance which leads to conclusion that we reject general hypothesis and accept auxiliary hypothesis that median basic set is higher than grade 3; respectively they are grades 4 or 5 . Often and always mentioned claims refer to observed company in course of implementing organizational changes. It is only in two questions instructed by long-term companies a median equal to or less than the rating 3 on the scale. Therefore, for questions: employees show initiative to engage in the process of change and- change management. 
teams are formed, hypotheses for this test are following:... $\eta \neq 3$ The zero hypothesis claims that median basic set is equal to 3 , while the first simulation hypothesis asserts that median basic set is different from grade 3 on the scale of questionnaire related to the success of change management.

\section{Wilcoxon Signed Rank Test:}

Test of aedias $=3,000$ versus sedian ato a 3,000

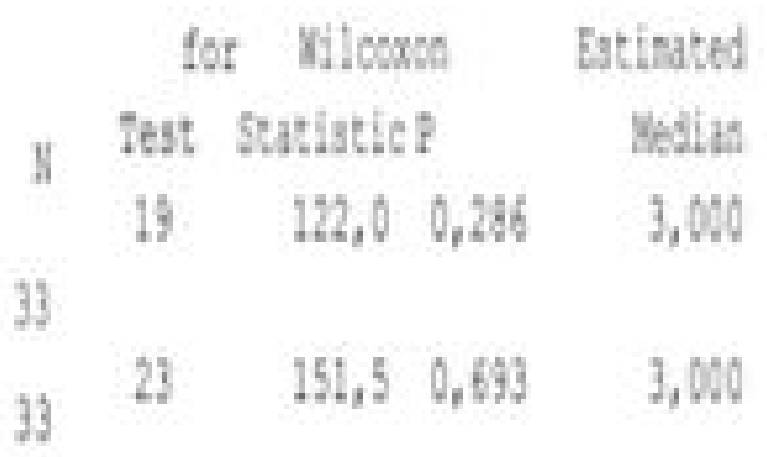


Practice has shown us that new way of working encouraged by initiative for change shows a certain pattern: it develops for a while and then weakens. At that time, initiatives for change were maintained only by a small group of "true believers". Initial momentum thus fails to reach its full potential. At the same time, many innovative ways of working are not experienced with wide application because they fail to prove to be sufficiently useful. Some modes of operation already show significant advantages in the beginning, but nevertheless do not spread based on the analysis that initiative is related to a professional team tasked with implementing business changes. The obtained $p$-values are of accepted degree of significance $(p=0.05)$ and hence on the basis of obtained p-values it is concluded that general hypothesis is accepted that median basic set to indicate claims equal to grade 3. Conclusion of testing the other auxiliary hypothesis should be divided into two parts, as is the case with testing. First conclusion refers to first testing of the median. By accepting an alternative hypothesis that median basic set is higher than grade 3 , or that there is a higher concentration of responses 4 or 5 that show a contrast than responses 1,2, 3 who show disagreement or indifference, we can claim that characteristic of the most long-term enterprises in Kosovo successfully deal with change management. Further testing of claims which in first test had a higher p-value than a significant value comes to a different conclusion. By accepting general hypothesis that median for above claims is same as three, it is concluded that it is not a characteristic of long-term enterprises that employees show initiative for change and that change management teams are formed. Considering the changes they have to manage and their time dimensions, extent to which individual changes are often carried out in the enterprise are in following results.

\section{Conclusion}

Each research carries with it certain limitations. Acceptance and appreciation of constraints allows better understanding of the obtained data and interpretation of results. General or zero hypotheses was testing existence of a link between managing organizational changes (as independent variables) and building sustainable competitive abilities (as dependent variables). Testing of hypothesis was carried out by

measure of logistic regression. Regression model pointed significance of independent variable management for organizational changes and with level of significance, therefore is less than assumed (5\%) a rejected zero hypothesis that argues that variable is insignificant in the model of favor of an auxiliary hypothesis that independent variable is significant in the model. Managing of organizational changes is connected with building a sustainable competitive ability of the company. Interpretation of the model shows that if the degree of agreement with claims related to organizational change management is one grade, then on average the likelihood of matching with claims for grade 3 according to grade 2 , for grade 4 according to grade 2 and grade 5 according to grade 2 , for claims related to sustainable competitive ability of undertaking an increase of an average of $6 \%$.In case of first auxiliary hypothesis was tested the existence of interdependence between life cycle of enterprises and organizational changes in longterm enterprises in Kosovo using the $\mathrm{X}^{2}$ Independence test. The response of the companies is based on answers from characteristics of a particular dimension of organization according to which they are classified into one of four phases of life cycle and a confirmatory answer to questions related to organizational changes for the stated phase of the life cycle. Since the empirical value of hisquare test is greater than test of the size of hisquare test, confidence level of significance has been rejected, zero hypothesis has been rejected in favor of first auxiliary hypothesis, respectively has been demonstrated existence of interdependence between phase of company's life cycle and organizational changes in longstanding enterprises in Kosovo. Second auxiliary hypothesis was tested whether characteristic of long-term enterprises was to successfully manage changes. Wilcoxon Signed Rank test was used to test hypothesis. The Wilcoxon Signed Rank test is to determine the median baseline and to identify 120 company concentrations according to grades. Given the possible estimates of the claim as the taken center value, average score are sometimes 3 - . After observing and calculating the middle value for each particular question in relation to another auxiliary hypothesis, the decision as to which hypothesis is accepted for a particular question was passed over the p-value. Therefore with a selected level of significance of $5 \%$, p- 
values are all in the row except for two questions, less than selected level of significance that led to conclusion that zero hypotheses is rejected and accepts another auxiliary hypothesis that the median basic set is higher than grade 3 , respectively that is grades 4 or 5. Often and always, claims are related to observed companies when implementing organizational changes. Only for two claims employees show initiative to engage in the change process and form teams for managing of changes, listed below value of the median. Therefore, test was repeated for these claims, but median remained at the level of grade 3 . Conclusion of test is that in most of long-term enterprises there are characteristics of successful change management, with emphasis on the fact that employees are showing a lesser degree of inclusion in the process of change and to create teams of change management. Third auxiliary hypothesis evaluated development of the system for implementation of development strategies in long-term enterprises in Kosovo. Wilcoxon Signed Rank test was also used to test hypothesis. With a selected level of significance of $5 \%$, the p-values of all assertions are less than selected level of significance leading to conclusion that general or zero hypothesis is rejected and accepts third hypothesis that median basic set is higher than grade 3 that is, 4 or 5, I agree and I strongly agree with the evaluations of observed companies on claims that relate to development of system for implementation of development strategies. It has been proven that long-term companies in Kosovo have developed a system for implementing development strategies. Taking into account results of the research, it can be said that long-standing companies in Kosovo recognized the importance of managing of change and within their businesses foster successful change management. Realizing that long-term success of the company is essential for development strategy; long-term companies in Kosovo have developed a system of implementation of mentioned strategies. Longterm companies in Kosovo knew how to manage individual phases of the life cycle, responding to the demands of environment and implementing necessary changes. They recognized importance of active management of life cycle line, managing changes in construction of a sustainable competitive ability of the company. Recommendations based on our empirical research on longevity of companies in Kosovo, we can give following recommendations for sustainability in company operations: - Companies that do not have a development strategy will never be able to create a competitive advantage and will always be vulnerable to all activities and strikes of competition. A system that does not have a long-defined mission and vision is doomed to failure. - to strengthen fiscal consolidation through the realization of higher revenues and at the same time to conduct savings and aim is to achieve primary surplus - that is, to achieve a surplus before payment of the debt, including interest and principal. - finding a sustainable solution for restructuring enterprises as well as continuing reforms of public enterprises. Companies should always have high standards of logistics services, which they regularly monitor and implement on every new market. The need for better management of money for capital investments. Entrepreneurs need flexibility, reliability, professionalism and precision as well as timely information on all current changes in functioning of company and compliance with laws. - For Labor market: it is necessary to reintroduce workers in restructuring into labor market to continue rationalization of the public sector and to increase capacity of the National Employment Service. Accounting is an important factor in decision making in every company. In order to make quick and good decisions, companies need accurate and effective reporting at any time.

\section{References:}

B. Davis, Mastering Organizational

[1] Change Management, J. Ross Publishing, 2017, p. 264.

J. Little, P Verdonk, Lean Change

[2] Management: PRÁCTICAS

INNOVADORAS PARA EL MANEJO DEL CAMBIO ORGANIZACIONAL, Happy Melly Express, 2019, p. 157.

P. Gibbons, The Science of Organizational

[3] Change: How Leaders Set Strategy, Change Behavior, and Create an Agile Culture (Leading Change in the Digital Age Book 1), 2 Edition ed., Phronesis Media, 2019, p. 379.

W. Bridges,S. Bridges, Managing

[4] Transitions, 25th anniversary edition: Making the Most of Change, 4 Edition ed., Da Capo Lifelong Books, 2017, p. 208. 
[5] E.Cameron , M.Green, Making Sense of Change Management: A Complete Guide to the Models, Tools and Techniques of Organizational Change, Kogan Page, 2019, p. 544.

[6] J. Hayes, The Theory and Practice of Change Management, 5 th Edition ed., Red Globe Press, 2018, p. 592.

[7] D.McCabe, Changing Change Management: Strategy, Power and Resistance (Routledge Studies in Organizational Change \& Development), Routledge, 2020, p. 228.

[8] G.Abudi, Implementing Positive Organizational Change: A Strategic Project Management Approach, J. Ross Publishing, 2017, p. 264.

[9] L. J. Marcus , E. J. McNulty , J. M. Henderson , B.C. Dorn , D. Gerge, K.T. Collins, You're It: Crisis, Change, and How to Lead When It Matters Most, Hachette Audio, 2019.

[10] F.Herzberg, "One More Time: How Do You Motivate Employees? (HBR Bestseller)," Harvard Business Review , pp. 65-73, 2020.

[11] G. Blokdyk, Software Change Management A Complete Guide, 5starcooks, 2020, p. 308.

[12] J. Grenny, K.Peterson, Influencer The New Science of Leading Change Second Edition, Pinterest, 2020.

[13] P. Gibbons, IMPACT: 21st Century Change Management, Behavioral Science, Digital Transformation, and the Future of Work (Leading Change in the Digital Age Book 2), Phronesis Media, 2019, p. 277.

[14] E.Cameron , M. Green , Making Sense of Change Management: A Complete Guide to the Models, Tools and Techniques of Organizational Change, 5 Edition ed., Kogan Page, 2019, p. 554.

[15] G.Abudi, Implementing Positive E-ISSN: 2224-3496
Organizational Change: A Strategic Project Management Approach, J. Ross Publishing, 2017, p. 264.

\section{Creative Commons Attribution License 4.0 (Attribution 4.0 International, CC BY 4.0)}

This article is published under the terms of the Creative Commons Attribution License 4.0

https://creativecommons.org/licenses/by/4.0/d eed.en_US 